\title{
ALGUMAS CONSIDERAÇõES SOBRE A PESQUISA DE CAMPO EM GEOGRAFIA AGRÁRIA
}

\author{
Fernanda Thomaz*
}

\section{RESUMO:}

Desenvolvo uma pesquisa de mestrado com o objetivo de compreender as conquistas, os avanços, os obstáculos, os impasses e os limites de uma cooperativa de produção agropecuária (CPA). Com essa finalidade, a pesquisa foi proposta aos camponeses da Copava (Cooperativa de Produção Agropecuária Vó Aparecida), da agrovila III, do assentamento Pirituba, pertencente ao Movimento dos Sem-Terras (MST), localizado nos municípios de Itapeva e Itaberá, sudoeste do Estado de São Paulo, Brasil. Intencionando construir a análise por meio da dialética materialista, uma parte essencial da pesquisa torna-se a coleta de dados feita com base em trabalhos de campo, não se querendo afirmar, com isso, que o trabalho de campo seja o único meio de construir uma pesquisa por meio da dialética. A importância do trabalho de campo consiste em fornecer bases mais seguras para a posterior discussão teórica e a melhor compreensão da realidade estudada. Além disso, com essa pesquisa, procuro me inserir na realidade camponesa não apenas como pesquisadora que observa, que busca compreender uma dada realidade, mas como uma pesquisadora que deseja ajudar a construir um mundo mais justo e igualitário. Dessa forma, tenho sido levada a refletir sobre o que é uma pesquisa participante e, principalmente, um pesquisador-participante. O objetivo do presente texto é iniciar uma discussão acerca do processo de inserção do pesquisador na comunidade estudada e do uso da técnica do gravador como forma de registro de informações, sempre a partir da minha prática pessoal de pesquisa em geografia agrária.

\section{PALAVRAS-CHAVE:}

geografia agrária, resistência na terra, campesinato, trabalho de campo, pesquisa participante.

\begin{abstract}
:
I develop a research aiming to understand the achievements, progress, obstacles, deadlock and limits of a agricultural production cooperative (CPA). To this end, the survey was proposed to the farmers of Copava (Cooperativa de Produção Agropecuária Vó Aparecida), of the agricultural community III, situated at Pirituba settlement, belonging to the Movimento dos Sem-Terras (MST), located in the municipalities of Itapeva-Itaberá, southwestern of the State of Sao Paulo, Brazil. Meant to build the analysis based on the dialectical materialism, the bulk of the research becomes the data collected based on fieldwork because it is this that will provide the foundations for further theoretical discussion and understanding of the reality studied. In addition, with this research I try to insert me into the peasant reality not only as a researcher who observes that and seeks to understand a given reality, but as a researcher who wants to help to build a more egalitarian and just world. Thus I have been compelled to think about what is a participant research and, especially, a participant-researcher. The purpose of this paper is to start a discussion about the process of inclusion of the researcher in the community studied and the use of the recorder as a means of recording information, always from my personal practice of research in agrarian geography.
\end{abstract}

\section{KEYWORDS:}

agrarian geography, resistance in the land, peasantry, fieldwork, participatory research.

*Aluna de mestrado do programa de pós-graduação da FFLCH/USP. Orientadora: Proa. Dra. Valéria de Marcos. E-mail:fegeo@usp.br 


\section{A Importância da pesquisa de Campo}

Uma primeira clareza que um pesquisador em geografia deve ter é sobre a própria importância do trabalho de campo. Lembremos que muita informação e muito suposto "conhecimento" são gerados somente através de informação secundária, ou seja, fala-se e escrevese sobre uma comunidade sem jamais tê-la visitado. A esse propósito ver a análise de Wooldrige e East $^{1}$ :

O primeiro princípio que se há de afirmar é o seguinte: para o geógrafo, como para outros especialistas que realizam trabalhos de campo, o terreno, e não os mapas, constitui o documento primário. Isso é indiscutivelmente verdadeiro nos domínios da pesquisa, embora os professores lidem necessariamente com regiões que jamais viram. Efetivamente, pouco respeito hão de impor os estudos que visem a aumentar o saber, mas sejam baseados inteiramente em fontes secundárias. (...) 0 geógrafo profissional é capaz de perceber configurações e relações totalmente ignoradas pelos moradores da região e, em certo sentido, conhecê-las em primeira mão. No entanto, qualquer pessoa dotada de espírito científico ou familiarizada com os padrões de estudo geralmente aceitos será levada a encarar com suspeição um trabalho, excelente embora, que não esteja informado no conhecimento do terreno. (pp. 172-173)

Considerando a importância do trabalho de campo na formação dos profissionais em geografia, sejam bacharéis, sejam professores, é sempre necessário elaborar uma análise de como ele está sendo encarado nas disciplinas. Pois, sem ele, pode haver uma enorme distorção entre o conhecimento adquirido e a verdadeira realidade, já que, devido a vários fatores, o trabalho de campo pode ser relegado a segundo plano ou até mesmo inexistir na formação, acarretando grande prejuízo para a construção de um conhecimento mais condizente com a realidade. Com isso, não se está afirmando que o trabalho de campo, por si só, poderá corrigir tal falha na formação do pesquisador em geografia, pois a sua postura em campo, seu empenho e esforço em compreender outras visões de mundo e outras experiências, o uso correto de técnicas adequadas, a metodologia adotada, dentre outros aspectos, é que poderão culminar numa pesquisa bem feita. Esses aspectos remetem à interferência do pesquisador nos resultados da pesquisa sobretudo nas ciências humanas, onde ele também participa do campo de ação da pesquisa. A esse respeito ponderou Cicourel $^{2}$ (p. 98):

Os problemas encontrados na observação, interpretação, registro e na decisão sobre a importância de dados para uma teoria relevante surgem na pesquisa de campo porque o observador é parte do campo de ação. O problema metodológico crucial que aqui surge é conseqüência da diferença entre a realidade física, tal como é descrita pelo cientista físico, e a realidade social, tal como é descrita pelo cientista social. Schultz ${ }^{3}$ coloca essa diferença na seguinte passagem:

Este estado de coisa se baseia no fato de que há uma diferença essencial na estrutura dos objetos do pensamento ou construtos mentais formados pelas ciências sociais. Cabe ao cientista natural, e somente a ele, definir, de acordo com as regras processuais de sua ciência, o seu campo de observação e determinar os fatos, dados e acontecimentos (dentro desse campo) que sejam relevantes para os problemas ou para o objetivo científico ao seu alcance. Nem são esses fatos ou acontecimentos selecionados previamente, nem é o campo de observação interpretado previamente. O mundo da natureza, tal como é explorado pelo cientista natural não "significa" nada para as moléculas, átomos e elétrons que nele existem. O campo de observação do cientista social, entretanto, quer dizer, a realidade social, tem um significado específico e uma estrutura de relevância para os seres humanos que vivem, agem e pensam dentro dessa realidade. Fazendo uso de uma série de construtos do senso-comum, eles selecionaram e interpretaram previamente este mundo vivenciado como a realidade de suas vidas cotidianas. São estes objetos de pensamento que determinam, por motivá-los, o 
comportamento deles. Os objetos de pensamento construídos pelo cientista social com a finalidade de dar conta desta realidade social, têm que estar baseados nos objetos de pensamento construídos pelo senso-comum dos homens que vivem sua vida cotidiana dentro de seu mundo social.

O papel do pesquisador na pesquisa em ciências sociais como um todo, e na geografia, em particular, adquire total importância para o resultado da pesquisa. É ele quem escolhe, mesmo inconscientemente, o que irá observar com maior ou menor atenção. Não significando, contudo, como chamou a atenção Cicourel, que - campo de significados escolhido pelo pesquisador seja semelhante ao campo de significados dos pesquisados. Isso exige do pesquisador uma reflexão constante sobre a sua própria postura no interior da comunidade, e uma disposição para rever o que já foi feito. Pode acontecer, inclusive, de haver a necessidade de rever o próprio objetivo da pesquisa, porque em campo encontrou-se uma situação bastante diferente daquela que havia motivado a pesquisa.

\section{A Chegada à Comunidade}

Quando se chega a uma comunidade, muitas dúvidas surgem para o pesquisador principiante como, por exemplo: qual a primeira pessoa a quem se deve dirigir? Como perceber a melhor hora de perguntar? Quais perguntas fazer para não ser nem parecer indiscreto? Como se constrói uma relação de confiança com as pessoas da comunidade? Como pedir para fazer uma entrevista? Quais pessoas entrevistar? Qual a melhor formar de encaminhar uma entrevista? Essas são apenas algumas dúvidas que surgem para um pesquisador principiante. Mas talvez sejam questões que acompanhem toda a vida de um pesquisador e, conforme se vai aprofundando na prática da pesquisa, elas se tornem cada vez mais importantes.

De qualquer maneira penso que a primeira clareza que um pesquisador em geografia agrária deve ter, sobretudo se for o primeiro ou primeiros contatos com a realidade rural, é que ele está pesquisando sujeitos sociais diferentes de si mesmo. Claro está que existe a possibilidade de encontrar diferenças em qualquer interlocutor, mas quando se trata de sujeitos sociais rurais seu modo e ritmo de fala, seu fluxo de pensamento, sua maneira de analisar e interpretar o mundo podem ser bem distintos do pesquisador. Este, em consequência, precisará esforçar-se para não se projetar "acima" das ideias de seus interlocutores, incorrendo no erro de compreender a sua realidade a partir da lógica do pesquisador. Por isso nesse texto busco fazer um pequeno histórico dos trabalhos de campo para a Copava, minha área de pesquisa, procurando mostrar como foi se intensificando o contato com meus interlocutores.

Na disciplina de geografia agrária do curso de graduação em geografia eu já havia visitado o assentamento Pirituba, localizado no sudoeste paulista, parte em Itapeva, parte em Itaberá. A fazenda Pirituba possui 17.500 hectares, dos quais apenas parte foi conquistada pelos camponeses. O restante é dominado por um grupo de holandeses capitalistas que já arrendavam a terra na época da ocupação do MST. O processo de ocupação da fazenda iniciou-se em 1981, com o grupo que viria a formar a agrovila I. Nos anos posteriores, outras partes da fazenda foram sendo ocupadas, totalizando hoje seis agrovilas. Cada agrovila possui autonomia em relação às demais quanto à organização de seus processos produtivos.

Como eu não possuía mais nenhum contato com os assentados da Pirituba, o primeiro passo foi contactar o MST de São Paulo, que me passou o telefone de Luís, professor do assentamento e assentado na agrovila VI. Liguei para ele, que me disse para procurá-lo quando visitasse 0 assentamento. Quando nos encontramos, em janeiro de 2007, contei sobre a minha atuação profissional, ou seja, professora de geografia da prefeitura de São Paulo, e que gostaria de continuar os estudos em geografia, intencionando realizar uma pesquisa de mestrado sobre o cooperativismo no assentamento Pirituba. Ele muito gentilmente me levou para conhecer cinco das seis agrovilas que formam o 
assentamento para que eu obtivesse uma visão geral da cooperação no assentamento. O objetivo de minha visita era reconhecer a viabilidade de uma pesquisa sobre a cooperação na Fazenda Pirituba. Para isso permaneci uma semana em campo. Mesmo não tendo visitado a agrovila II, soube que também lá não mais existia CPA. O panorama predominante no assentamento era a existência de cooperativas de crédito, comercialização, mas não CPAs. Desse modo, confirmava-se que a Copava era a única cooperativa a funcionar nesses moldes.

Muitas questões surgiram nesse primeiro trabalho de campo: como me apresentar aos camponeses das agrovilas? Como dizer que eu gostaria de fazer uma pesquisa sem que eles se sentissem vigiados ou pressionados? Como justificar a eles meu interesse? Diante dessas dúvidas, adotei um princípio que utilizo sempre, a sinceridade. Apresentei-me como eu era, uma estudante despertada para a questão agrária e os problemas camponeses, e que pretendia contribuir de alguma maneira com a luta que os camponeses já vêm travando há anos.

No período de 15 a 19 de julho de 2007 realizei um segundo trabalho de campo para o assentamento Pirituba, onde permaneci por quatro dias. Como na primeira pesquisa de campo não consegui visitar a agrovila II, nesse segundo trabalho foi uma oportunidade de conhecê-la, além de refazer a visita às outras agrovilas. Nessas visitas o foco foi conversar com os assentados, conhecer um pouco dos problemas enfrentados por eles e, mesmo que superficialmente, conhecer o papel das cooperativas na superação dos problemas. Com isso tive a oportunidade conhecer melhor o assentamento e conversar com camponeses que participaram da ocupação da fazenda, na década de 80 . Além disso, obtive uma visão um pouco mais aprofundada da opinião deles sobre as cooperativas. Com esse trabalho tive a clareza da impossibilidade de estudar todo o assentamento Pirituba, restringi a área de estudo à Copava, e ofereci a pesquisa ao Zezinho, então presidente da cooperativa. Também com Zezinho utilizei o mesmo princípio que já havia aprendido no primeiro trabalho de campo, a sinceridade. Disse-lhe que, apesar de ter nascido no urbano, minhas raízes eram camponesas por herança de meus avós paternos e maternos. Além disso, gostaria de contribuir com a luta pela resistência na terra através do estudo de uma cooperativa de produção agropecuária, como a Copava.

De 5 a 12 de julho de 2008 realizei um terceiro trabalho de campo para o assentamento Pirituba. Nesse trabalho restringi-me à agrovila III, já a minha área de estudo, para coleta de dados e informações sobre a Copava. Durante o tempo de permanência na cooperativa, entrevistei cinco camponeses, inclusive três que participaram da ocupação da fazenda. Também pude conhecer um pouco de sua estrutura organizativa. Permaneci dois dias acompanhando a rotina de trabalho no bar da cooperativa e dois dias na ciranda infantil (creche). Durante as entrevistas notei que vários interlocutores eram cautelosos ao falar, expressando-se num ritmo lento e pausado. A minha primeira interpretação, apressada, era de que eles desejavam terminar a entrevista. Porém o pesquisador precisa considerar que ele é um estranho na comunidade, e o entrevistado, ao perceber que faz parte de outro "universo social", pode procurar controlar a sua fala, adequando-a ao que entende ser a fala do outro e também selecionando o que deve ser dito e o que deve ser ocultado. Percebi isso porque quando eu acreditava que a entrevista já se encerrara com o silêncio do meu entrevistado, de repente ele tornava a falar, e muito. Com isso, eu que já havia desligado o gravador, perdi muita riqueza de detalhes. Os silêncios e as pausas do entrevistado são outros pontos importantes da pesquisa de campo, é preciso compreendê-los, pois geralmente tem um significado que deve ser apreendido a partir do contexto social em que este se insere e não deve ser compreendido como uma característica geral de toda uma classe social.

Em janeiro de 2009 realizei o quarto trabalho de campo para a Copava, onde permaneci dez dias na agrovila, de 05 a 15 de janeiro, conhecendo e trabalhando nos setores agrícola, bar, suinocultura, pecuária, e realizando entrevistas nos diversos setores. Também 
participei durante três dias da carpida do arroz, junto com os camponeses, e realizei entrevistas com alguns deles, para conhecer o trabalho e compreender como se estrutura esse setor. Durante todo esse tempo me inseri na rotina de trabalho sem incomodá-los nem atrapalhar o trabalho. No setor de suinocultura acompanhei o trabalho por dois dias. No primeiro, conheci as instalações - a mangueira - os animais adultos, os reprodutores e os leitões, e realizei entrevista com um dos trabalhadores responsáveis pelo setor. No segundo dia busquei cooperar com o trabalho, misturando ração para os porcos. Além disso, visitei e adquiri informações sobre o biodigestor, sistema gerador de biogás a partir do estrume do porco.

No setor de segurança não acompanhei o trabalho, mas realizei entrevista com um dos trabalhadores do setor para conhecer a história da luta pela terra, já que este associado foi um dos primeiros ocupantes da fazenda, busquei conhecer também a rotina e os riscos de seu trabalho. No bar acompanhei o trabalho todas as noites, ajudando no atendimento no balcão e na elaboração de salgados.

No setor de pecuária, estive por um dia e meio. No primeiro dia conheci a mangueira, as vacas, o touro e os bezerros. Participei da ordenha, da distribuição de leite aos cooperados e do corte de ração. Também realizei entrevista com dois trabalhadores do setor. No segundo dia tornei a participar da ordenha e da distribuição de leite, na parte da manhã, e à tarde juntei-me ao mutirão para carpir arroz, por ser o trabalho prioritário para todos.

Em fevereiro de 2009, durante dez dias, realizei um quinto trabalho de campo para a Copava. Durante dois dias acompanhei o trabalho das camponesas na horta medicinal na limpeza do terreno (carpa) e na feitura dos canteiros. Após o trabalho realizei entrevista com uma camponesa do setor para compreender melhor as questões relacionadas a ele. Entrevistei um trabalhador do setor de oficina mecânica para conhecer a rotina do trabalho. Colaborei na elaboração de pães na padaria, e saí para vender pão com Jamil, um dos vendedores. Entrevistei dois membros da nova diretoria, o tesoureiro e o presidente, afim de compreender como eles estão encarando a nova atividade. Também entrevistei Zezinho, o antigo presidente da cooperativa. Além disso, conheci a área agrícola da Copaese (Cooperativa de Produção Agropecuária Sete de Setembro) e realizei entrevista com três antigos sócios dessa cooperativa, que também não quiseram participar da Copava.

\section{A Pesquisa Participante}

Com os diversos trabalhos de campo e o estreitamento da relação com os camponeses da Copava, a questão do compromisso da pesquisa com a comunidade foi tomando mais força. Na verdade, esse compromisso sempre esteve presente desde o início da pesquisa, mas com a convivência através dos trabalhos de campo ele foi se tornando cada vez mais necessário na medida em que eu me aproximei mais de questões centrais relacionadas à organização do grupo. Os impasses a que a comunidade chegou acerca do trabalho coletivo podem e devem ser discutidos por uma universidade comprometida com um mundo mais justo e igualitário. Sobre essa questão afirmou BRANDÃO (1987, p. 12):

Quando o outro se transforma em uma convivência, a relação obriga a que o pesquisador participe de sua vida, de sua cultura. Quando o outro me transforma em um compromisso, a relação obriga a que o pesquisador participe da sua história. Antes da relação pessoal da convivência e da relação pessoalmente política do compromisso, era fácil e barato mandar que "auxiliares de pesquisa" aplicassem centenas de questionários apressados entre outros que, escolhidos através de amostragens ao acaso "antes", seriam reduzidos a porcentagens sem sujeitos "depois". Isto é bastante mais difícil quando o pesquisador convive com pessoas reais e, através delas, com culturas, grupos sociais e classes populares. Quando comparte com elas momentos redutores da distância do outro 
no interior do seu cotidiano. Então a observação participante, a entrevista livre e a história de vida se impõem.

Com o estreitamento das relações com a comunidade e o conhecimento de suas dificuldades, surgiu uma reflexão importante. O pesquisador deve se envolver com os problemas e junto aos camponeses tentar buscar soluções ou deve assumir a postura de apenas compreender o significado dos problemas?

A resposta a essa questão é em grande parte de cunho pessoal, pois depende do modo como o pesquisador compreende a sua inserção na pesquisa e na própria sociedade. Há quem considere que o pesquisador não precisa assumir como seu os problemas de seus pesquisados. Mas há pesquisadores que acreditam na necessidade de envolvimento nas lutas de seu tempo. Sabendo que a escolha do tema de pesquisa não é fortuita e que vivemos em uma sociedade de classes, desigual e injusta, não há neutralidade da pesquisa nem do pesquisador. Penso que, se evitamos a nossa participação do lado dos camponeses, estamos assumindo nossa participação do lado dos que os exploram. Portanto, é impossível estar neutro e, qualquer que seja a escolha, ela deve ser feita conscientemente.

Contudo, com o andamento da pesquisa, percebe-se que surgem questões e problemas decorrentes do aprofundamento do conhecimento da realidade estudada, tomando a pesquisa rumos inesperados. Por exemplo, diante do objetivo de compreender o papel da produção coletiva camponesa na luta pela resistência na terra, tornou-se essencial conhecer as experiências históricas, como a russa, que se tornaram referência para o MST realizar esse tipo de organização da produção em seus assentamentos. Fez-se necessário compreender que tipo de sociedade era vislumbrada e o papel do campesinato na sociedade para os que propuseram pela primeira vez a produção camponesa coletiva, ganhando a pesquisa novos rumos que a projetaram para além da experiência imediata estudada.
Outra questão importante quando o pesquisador está inserido em uma comunidade é ter clareza de que ele é um "estranho" para o grupo, devendo, portanto procurar compreender a riqueza de opiniões existentes, reconhecendo que as contradições e opiniões diversas existem e fazem parte da construção da comunidade. Vejamos os seguintes exemplos de depoimentos de camponeses extraídos em trabalho de campo:

Era difícil, mas eu achava que naquele tempo era melhor do que agora. Não tinha separação de nada. Uma vez veio um padre. Veio celebrá uma missa, debaixo de uma árvore. Ele disse: "Olha gente, eu vou pedi uma coisa pra vocês, quando vocês tiverem a casinha de vocês, não se esqueçam de se unir como vocês são unidos agora". Naquele tempo era tudo igual, o que eu comia, ela também comia. Mas só que as coisas muda. Naquele tempo era difícil, mas na mesma hora era mais unido.

(Dona Zica, horta medicina da agrovila III, em entrevista concedida em julho de 2007)

Achei melhor o sistema de hora trabalhada. Cooperar com os companheiros. Dá pra ir na cidade, fazê uma compra, tem folga, tirá afastamento, né. A pessoa é livre daí. Não prende direto ao trabalho. Tem o momento livre da pessoa.

(Tuca, trabalhador do setor de suinocultura da Copava, em entrevista concedida em janeiro de 2009)

Esses dois depoimentos de camponeses da mesma agrovila mostram opiniões diferentes acerca da organização coletiva do trabalho camponês. Dona Zica mostra-se muito mais reticente e crítica com relação aos rumos que a cooperativa tomou após a mudança na forma da distribuição da renda, que antes era feita igualmente, por família, mas passou a ser feita por horas trabalhadas. Já Tuca, do setor de suinocultura, acha que o novo sistema é melhor porque possibilitou aos trabalhadores obterem momentos de descanso. Diante desses depoimentos, vê-se o quanto o trabalho de campo é essencial para a compreensão das contradições da realidade, sendo esta dinâmica e complexa, impossível de ser apreendida por um único 
depoimento. Isso faz com que seja necessário retornar várias vezes ao local da pesquisa, realizar entrevista com várias pessoas, de sexo e idades diferentes, e até com a mesma pessoa em momentos diferentes para analisar o significado da experiência na sua diversidade - o que significa fazer a devida contextualização dos depoimentos em relação a um determinado universo de relações sociais. Pois é possível que o pesquisador seja traído por sua própria visão de mundo, por suas crenças e convicções, atribuindo maior importância aos depoimentos que corroboram com a sua própria opinião.

Esse aspecto da pesquisa remete à questão do desencontro entre a cultura do pesquisador e a do pesquisado, como chamou a atenção José de Souza Martins no livro "A Chegada do Estranho":

Os diferentes textos que reúno neste livro tratam de um fenômeno que ainda não mereceu maior atenção dos sociólogos neste país - o do desencontro, que se expressa na importância social (e sociológica) que em nossa sociedade e em nossa cultura tem o estranho. Em princípio, o que vem "de fora", o que pertence a "outro mundo social", diverso do daqueles que sofrem o impacto e vivem a sua presença intrusa e incômoda. Em perspectiva diversa, e oposta, uns poucos falaram na presença "do índio no mundo do branco" ou "do negro no mundo do branco", analisando com competência as formas de ajustamento e transformação, de encontro, entre personagens de mundos étnicos distintos.

Há, porém, uma enorme riqueza sociológica na orientação e na situação oposta - a do desencontro, da estranheza, da resistência na persistente e, por ora, renovada experiência do aparentemente perdedor e derrotado. Elas nos falam de maneira densa sobre características e processos particulares desta sociedade. Uma sociologia do estranho e do estranhamento é um reclamo natural de uma sociedade de tradição corporativa, carregada de preconceitos sociais, que não passou pelos processos revolucionários que, em outros lugares, levaram à disseminação da igualdade, da contratualidade nas relações sociais e da cidadania. A nossa sociabilidade dominante é demarcada e bloqueada por enormes dificuldades no reconhecimento do outro, sua aceitação como outro, isto é, diferente, e igual. Se, de um lado, as ciências sociais têm reconhecido determinadas etnias, grupos, classes, como "estranhos" e procurado estudar e compreender as características da sua integração na sociedade "branca" e dominante, na sociedade de classes, o mesmo não têm feito na escala desejável com os que mandam, com mais razão ainda estranhos em relação aos dominados - índios, camponeses. Mesmo porque referida integração não tem se dado aqui nos mesmos termos em que ocorreu nos países modernos. Os alcançados pela expansão capitalista são freqüentemente lançados nas escalas inferiores da produção mercantil simples, como ocorre claramente com grande parte do nosso campesinato. Quando não são banidos para a miséria daquilo que entre nós se tornou uma condição permanente de muitos, e não transitória como em outras partes, que é a do exército industrial de reserva, lugar em que a situação de excluído (e de estranho) é alimentada por condições anômicas de vida (1991, pp. 11-12).

Esse trecho de Martins apresenta o importante aspecto dos desencontros e estranhamentos vivenciados por grupos subordinados e excluídos. Como o pesquisador, representante como é de uma instituição social dominante como a universidade, se insere nesse contexto? O mais comum é o pesquisador enxergar a comunidade estudada como estranha, ou seja, além de diferente, inferior à sua. Isso pode acarretar uma distorção no entendimento da realidade, pois desabona os sujeitos da pesquisa lançando suas opiniões e realizações numa esfera inferior. Como se fossem despreparados para serem sujeitos de sua própria vida. Sobre essa questão Alba Zaluar ${ }^{4}$ também elaborou uma análise:

A imagem que a pesquisa registra das classes populares é a de grupos locais que se identificam pela falta de, pela carência. Estas 
existem de fato e são o móvel de projetos políticos os mais variados, não necessariamente aquele que o pesquisador considera como o moderno, adequado, eficaz ou justo. O perigo é avaliá-los e encampálos segundo um modelo estereotipado de "participação democrática". Além disso, ao focalizar e tomar como decisivo e decidido o discurso sobre as carências materiais, o pesquisador apenas ajuda a fixar ou cristalizar a identidade negativa (pela falta) dessas classes (1986, p. 113).

Quando um pesquisador chega para estudar uma comunidade, portanto, mesmo inconscientemente é possível que ele se veja como superior, entendido, conhecedor, porque proveniente da cultura dominante que diz tentar compreender o mundo e assim buscar transformá-lo. Isso faz com que o pesquisador relegue a comunidade a uma posição de inferioridade, muitas vezes desvalorizando suas ações, práticas, crenças, etc. Além disso, como observou Zaluar, muitas das comunidades estudadas são materialmente carentes, fazendo com que o pesquisador atribua a elas valor menor por enxergá-las carentes. Ora, se por um lado a carência material realmente existe, por outro, ela pode não ser definidora do essencial que explica a comunidade, pois, há outros elementos que adquirem maior importância quando realmente percebidos pelo pesquisador. Para citar um único exemplo que encontrei, dentre tantos, em minha área de estudo, refiro-me ao depoimento já citado de Dona Zica, onde ela aponta a importância da cooperação e da igualdade, entre os camponeses que ocuparam a área que viria a ser a agrovila III do assentamento da fazenda Pirituba, para o surgimento da união entre eles. E que talvez essa união tenha ficado prejudicada quando passou a existir maior geração de renda.

Esse exemplo procura mostrar que o pesquisador precisa estar realmente aberto a novas visões de mundo, senão ele acabará por considerar a sua forma de estar no mundo e seus valores, como o correto, já que a sociedade capitalista da qual ele provém define o grau de sucesso ou fracasso pelo acúmulo de dinheiro e o poder aquisitivo que ele permite. Contudo é preciso reconhecer que o risco de o pesquisador interpretar a realidade de forma enviesada também pode ocorrer mesmo se ele se situa numa posição crítica em relação à ideologia capitalista. É fundamental, portanto, que o pesquisador mantenha-se sempre em uma posição autocrítica, analisando-se a cada etapa da pesquisa, seja ela de campo ou de gabinete.

\section{O uso do gravador}

Em todos os trabalhos de campo, as entrevistas foram registradas através da técnica do gravador. Essa técnica, como qualquer outra, possui vantagens e desvantagens. Uma vantagem importante foi apontada por QUEIROZ (1991, p. 74):

A grande diferença entre o registro da informação viva e o registro através da escrita, (...), está em que a informação viva provém diretamente do informante e de suas motivações específicas. Ao contrário, o questionário (para apresentar um exemplo), ou a entrevista com roteiro têm origem nas preocupações do pesquisador, isto é, são impostos ao informante como algo exterior a ele, tendo ele de se conformar com um ritmo de perguntas que não é o seu, com perguntas orientadas por motivações que não são as suas. Quando, no âmbito da coleta de uma história de vida, o informante conta um caso em determinado momento, é porque este caso tem para ele então um significado específico, que aparentemente pode não se ligar ao momento narrado, nem aos objetivos do pesquisador, porém não pode ser por este desprezado porque "faz sentido" com o restante do relato, numa ligação que precisa ser desvendada e que pode levar a tudo quanto estava subjacente à narração.

De fato, o uso do gravador associado à técnica de história de vida pode trazer surpresas enriquecedoras à pesquisa. Um exemplo pessoal foi quando entrevistei um camponês já idoso que participou da ocupação da fazenda desde o 
princípio. Após a conquista da terra e a estruturação da cooperativa, ele trabalhou em vários setores. Um dos setores foi o de segurança, onde trabalhava à noite. Talvez essa circunstância juntamente com o imaginário social sobre seres sobrenaturais podem ter aguçado a sua imaginação, pois ele via e ouvia seres "estranhos". Isso fez com que os camponeses implantassem um cruzeiro próximo à cabine onde ele ficava a fim de espantar os maus espíritos. A principio, minha pesquisa de mestrado não trata dessas questões, porém para que eu possa compreender a formação e a organização daquele território camponês, essa narrativa torna-se essencial. De acordo com QUEIROZ (1991, p. 75):

Verifica-se assim a riqueza de dados que esta técnica permite alcançar, uma vez que, além de colher aquilo que se encontra explícito no discurso do informante, ela abre portas para o implícito, seja este o subjetivo, o inconsciente coletivo ou o arquetipal. Em qualquer desses casos, são rumos novos que a investigação pode tomar, mas que se vinculam estreitamente com as próprias condições em que devem ser efetuados os registros, isto é, com as exigências de uma boa aplicação.

Uma desvantagem da técnica do uso do gravador, no entanto, é a possibilidade de inibição do informante. Entre os entrevistados sempre há os que já foram entrevistados outras vezes, que são lideranças ou porta-vozes da comunidade. Mas também sempre há os que nunca ou apenas circunstancialmente concederam entrevistas, e não gostam ou não estão preparados para falar. Por isso, quando se encontram diante do gravador, falam pouco ou só responde ao que foi perguntado. Uma forma de minimizar essa dificuldade é, em primeiro lugar, só entrevistar os camponeses após seu consentimento. Isso parece óbvio, mas, às vezes, o pesquisador está tão empenhado em obter informações que esquece que deve respeitar o desejo de seu interlocutor. Outra medida que ajuda a minimizar a inibição perante o gravador é esclarecer para o informante o objetivo da pesquisa e o que será feito com as informações fornecidas. No caso da pesquisa com camponeses que lutaram pela terra, isso é essencial porque foram pessoas perseguidas, que muitas vezes tiveram que conviver com jagunço disfarçado de camponês inserido no interior da comunidade.

Ao longo do texto procurou-se problematizar pontos fundamentais na relação pesquisador-entrevistado como: o reconhecimento do outro em sua diferença como um sujeito pleno de vontades e pensamentos próprios, e o respeito que o pesquisador deve desenvolver acerca das diferenças entre seu "universo social" e o dos seus interlocutores. Outro aspecto fundamental é saber ouvir e compreender as pausas e os silêncios, e o contexto em que são produzidos, para compreender o seu significado. Esses dois aspectos remetem à própria posição do pesquisador, sobretudo em ciências humanas, onde ele mesmo é parte fundamental da coleta de dados e sua interpretação, ou seja, da produção do conhecimento. De maneira muito sucinta procurou-se também iniciar uma reflexão acerca do uso do gravador na pesquisa de campo, mostrando a vantagem no registro de informações, e a possível desvantagem de inibição dependendo do interlocutor.

Como foi dito no início do texto, o meu objetivo é não apenas compreender um pouco melhor a realidade camponesa. Isso me traria títulos e a possibilidade de uma melhoria na minha atuação profissional, mas não faria de mim uma pesquisadora comprometida com as pessoas que gentilmente permitiram que eu entrasse em suas casas, compartilhasse de sua comida e compreendesse a sua história e a sua luta. Portanto, meu objetivo é, a partir do conhecimento gerado com o estudo da Copava, começar um mapeamento das experiências camponesas de trabalho coletivo e comunitário para formar um banco de dados que possa ser útil aos camponeses que desejem conhecer outras experiências de organização do trabalho, que não a individual, e quiçá queiram organizar o trabalho de outra forma. 


\section{Notas}

${ }^{1}$ S. W. Wooldridge e W. Gordon East. Espírito e Propósitos da Geografia. Rio de Janeiro: Zahar editores, s/d..

${ }^{2}$ Aaron Cicourel. Teoria e método em pesquisa de campo. In. Desvendando máscaras sociais. Rio de Janeiro: Livraria Francisco Alves Editora, 1980.
3 Alfred Schutz. "Concept and theory formation in the social sciences", Journal of philosophy, LI (abril de 1954), pp 266-267.

4 Alba Zaluar. A Aventura Antropológica Teoria e Pesquisa. Rio de Janeiro: Paz e Terra, 1986.

\section{Bibliografia}

BRANDÃO, Carlos Rodrigues (org). Repensando a Pesquisa Participante. São Paulo: Brasiliense, 1987.

BRANDÃO, Carlos Rodrigues (org). Pesquisa Participante. São Paulo: Brasiliense, 1999.

CARDOSO, Ruth. A Aventura Antropológica. São Paulo: Paz e Terra, 1986.

CICOUREL Aaron. Teoria e método em pesquisa de campo. In: Desvendando máscaras sociais. $2^{a}$ edição. Rio de Janeiro: Livraria Francisco Alves Editora, 1980.

MARCOS, Valéria de. Comunidade Sinsei: Utopia e Territorialidade. São Paulo: FFLCH/USP, Dissertação de Mestrado, 1996.
MARTINS, José de Souza. A Chegada do Estranho. São Paulo: Hucitec, 1991.

OLIVEIRA, Ariovaldo Umbelino de. A geografia agrária e as transformações territoriais recentes no campo brasileiro. IN: Novos Caminhos da Geografia. São Paulo: Contexto, 1999.

QUEIROZ, Maria Isaura Pereira de. Variações sobre a técnica de gravador no registro da informação viva. São Paulo: Biblioteca básica de ciências sociais, 1991.

ZALUAR, Alba. A Aventura Antropológica - Teoria e Pesquisa. Rio de Janeiro: Paz e Terra, 1986.

WOOLDRIDGE, S. W. e EAST Gordon W. Espírito e Propósitos da Geografia. Rio de Janeiro: Zahar editores, s/d.

Trabalho enviado em outubro de 2009

Trabalho aceito em dezembro de 2009 